\title{
Psychotherapy and Mental Retardation: What's the Use?
}

Jolyn Welsh Wagner, MD

Sinai Hospital, Detroit Michigan

Follow this and additional works at: https://jdc.jefferson.edu/jeffjpsychiatry

Part of the Psychiatry Commons

Let us know how access to this document benefits you

\section{Recommended Citation}

Wagner, MD, Jolyn Welsh (1988) "Psychotherapy and Mental Retardation: What's the Use?," Jefferson Journal of Psychiatry. Vol. 6 : Iss. 2 , Article 7.

DOI: https://doi.org/10.29046/JJP.006.2.005

Available at: https://jdc.jefferson.edu/jeffjpsychiatry/vol6/iss2/7

This Article is brought to you for free and open access by the Jefferson Digital Commons. The Jefferson Digital Commons is a service of Thomas Jefferson University's Center for Teaching and Learning (CTL). The Commons is a showcase for Jefferson books and journals, peer-reviewed scholarly publications, unique historical collections from the University archives, and teaching tools. The Jefferson Digital Commons allows researchers and interested readers anywhere in the world to learn about and keep up to date with Jefferson scholarship. This article has been accepted for inclusion in Jefferson Journal of Psychiatry by an authorized administrator of the Jefferson Digital Commons. For more information, please contact: JeffersonDigitalCommons@jefferson.edu. 


\title{
Psychotherapy and Mental Retardation: What's the Use?
}

\author{
Jolyn Welsh Wagner, M.D.
}

\section{INTRODUCTION}

The lack of adequate treatment opportunities for mentally retarded people with emotional disturbances has been well documented $(11,14,9,16,8,21,10,19)$. A high prevalence of psychopathology, estimated at 4-5 times that of the non-retarded population $(8,10)$ identifies a population extremely vulnerable to emotional problems. Although advocates from many disciplines, including psychiatry, (15) have worked diligently since the early 20 th Century to eliminate massive institutionalization, sterilization, and isolation of the retarded from society's defensive arsenal, the mental health field, especially psychiatry, has failed to meet current needs with appropriate clinical services.

"Management" has been a primary goal for behavioral techniques and medications as adjuncts for "control". Increased visibility in the community appears to necessitate the transformation of the "retarded into a nice, quiet obedient individual who always does what he is told and continually shows his appreciation" (9). The use of psychotherapy to successfully treat emotional problems diagnosed in the retarded has been well described $(18,3,9,5,16$, $22,4,19,10,15,21)$, Despite this, the use of psychotherapy with persons who are mentally retarded has decreased (8); mental retardation continues to label an individual as an "inappropriate candidate" for psychotherapy. There is a persistent pessimism surrounding the use of psychotherapy, partially due to a lack of education about mental retardation. Common myths $(9,21)$ that handicap therapists with "unwarranted despair" (16) include: 1) the limited value of psychotherapy in a population incapable of insight; 2) the inability of the mentally retarded to experience real conflict; 3) the lack of depth of emotional experience (the image of the carefree, happy retardate); 4) the dangers of encouraging retarded individuals to express emotions; and 5) the expectation of minimal improvement.

This paper attempts to demonstrate the usefulness of psychotherapy with mildly retarded individuals, with a basic assumption that the availability of psychotherapy can be increased by educating psychiatrists about mental retardation and examining common countertransference reactions that deter effective work with this population. A brief review of the $D S M-I I I-R$ classification of mental retardation introduces a discussion of the emotional difficulties that commonly present in affected individuals; the concept of dual diagnosis is also 
included, emphasizing the spectrum of psychopathology and the need for careful evaluation and appropriate treatment. The goals of psychotherapy and the role of the therapist is explored and then demonstrated in a case report of time-limited group therapy.

\section{MENTAL RETARDATION}

The term "mentally retarded" is applied to a very large (approximately $1 \%$ of the population) (17), very heterogeneous (greater than 350 known etiologies) (10) group with very different degrees of disability. The current DSM-III-R (17) defines this group as having "significant subaverage general intellectual functioning, defined as an IQ of 70 or below", and subdivides the group into profoundly retarded (IQ 20 or less), severely retarded (IQ 20-24 to 35-40), moderately retarded (IQ 35-40 to 50-55) and mildly retarded (IQ 71 to 84). Borderline intellectual functioning is designated by a $\mathrm{V}$ code and does not fulfill $D S M-I I I-R$ diagnostic criteria. Despite frequent need for assistance, these mildly retarded individuals are often considered ineligible for services available to the "truly" retarded (9). Impaired intellectual functioning is not sufficient to make the diagnosis of mental retardation; the DSM-III-R requires demonstration of "significant deficits or impairments in adaptive functioning . . . social skills, communication, and daily living skills ... personal independence and social responsibility . . . before age 18 ."

The $D S M-I I I-R$ criteria may be cautiously used to understand special problems and design appropriate interventions. For example, profoundly or severely retarded individuals, diagnosed in infancy, are more prone to serious medical problems, associated disabilities (congenital defects, seizures, deafness, blindness) and carry a mortality rate 7-30 times higher than the general population (10). Motor development is poor and language skills minimal. Primitive behaviors such as mouthing, licking toys, negativism and perseveration are common (10). Menolascino (9) describes the lack of a functional ego and an "amorphic" personality structure, but also emphasizes that such children do establish eye contact and are capable of responding interpersonally with appropriate stimulation.

Individuals with moderate retardation (10\% of the retarded population) often demonstrate many of the genetic, biochemical and neurologic etiologies that characterize the severely retarded $(15,17,9)$, with a similar spectrum of associated handicaps. Significant language and speech impairments restrict the child's ability to communicate distress. These children are more aware of developmental expectations, but their limited repetoire of skills and fragile defenses makes failure and frustration common, frequently expressed through hyperactivity, impulsivity, rapid mood swings, and regression (9). Such behaviors are responsible for the frequently reported rejection by parents and peers, uncommon with more severely retarded children. Although institutionalization was common in the past, the majority of moderately retarded individuals can 
function with close supervision in sheltered workshops and supervised group homes (17).

Mildly retarded individuals, (85\% of the retarded population) (17) are the primary focus of this paper. Unlike the severely and moderately retarded, these individuals are less distinguishable from non-retarded children before school age. Although some degree of social impairment and developmental lags in play and impulse control may be present before school age (15), physical stigmata are uncommon $(15,10)$ and life expectancy usually normal $(10)$. As a result, parental expectations remain high and the acknowledgement that a problem exists is delayed. Confirmation that a child has a "learning disability" is uncommon before ages 6-9, occurring at a crucial developmental period where tasks centered around school performance and play build a sense of mastery, competency, and self-esteem (7). The failure to master school work that grows increasingly abstract and social relationships that become increasingly complex contributes to a sense of inadequacy. The mildly retarded individual's deficits in language and abstraction equips him/her with concrete thought processes, rigid primitive ego defenses (15), and prolonged dependency needs. This is poor preparation for separation-individuation and the expectations of the adult world. Turecki (21) emphasizes "this critical dilemma, (that) becomes very evident if one reviews again a few common expectations of young adults and compare these with the developmentally determined realities pertaining to retarded young adults. The expectations are maturity, independence, ability to apply abstract thinking to problem solving, assumption of responsibility for oneself and then others, and competition for occupational opportunity. In reality, the retarded individual is immature, dependent, uses simple concrete thinking, and needs extra support and guidance."

Mildly retarded individuals are painfully aware of their difficulties and failures. Reiss and Benson (12), in a preliminary study, examined the high level of awareness that mildly retarded individuals have of the "negative social factors" which they defined as labeling, rejection, ridicule expressed by peers, family and strangers, segregation, infantilization, social disruption from loss of family members, friendships and residential changes, restricted opportunities and victimization. They must cope with their own awareness of parental disappointment and chronic sorrow (18).

Language and speech deficits, although less severe in the mildly retarded, are common (1), and interfere with the expression of need fulfillment. Articulation difficulties cause frustration, isolation and impatience with peers who have difficulty understanding. Receptive problems increase the loneliness and frustration that results from attempts to interact with family and peers, creating an "eternal toddler" (16) trapped by an inability to comprehend the meaning of certain ideas or express them effectively. Mainstreaming and community placement creates greater expectations and demands for appropriate interactions with an ever scrutinizing unsympathetic "normal population." 


\section{THE DUAL DIAGNOSIS}

An examination of the problems experienced by the mentally retarded strongly supports the generally acknowledged susceptibility to emotional and personality disturbances. Emotional-behavioral disturbances (after degree of intellectual impairment) remains the most common reason given for institutionalization (10).

There is general agreement that the mentally retarded exhibit the entire range of psychopathology $(9,10)$. Most attempts to quantitate the frequency of mental illness dealt with institutionalized populations (10), grossly exaggerating the prevalence of severe psychopathology. Community studies also support the idea that mental retardation increases the susceptibility to psychoses. "Neurotic" illnesses such as conversion reactions, anxiety disorders, obsessive-compulsive disorders, and phobias are more commonly observed among mildly retarded individuals than the moderately or severely retarded $(10,9)$; such disorders have been estimated to affect at least $4-6 \%$ of all retarded, a rate greater than that observed in the non-retarded population. Personality disorders here, loosely defined as chronically maladaptive behavior, have been reported to be as high as $27 \%$ (10) among community based mentally retarded people. Suicidal behavior, alcoholism, and drug addiction have not been well studied, but will require further investigation as more mentally retarded people face the frustrations of community living.

Such a large spectrum of psychopathology requires an equally broad range of treatment expertise. The management of psychotic illness and severe behavioral problems is discussed elsewhere $(15,23)$. It must be emphasized that careful evaluation is required to formulate an appropriate treatment plan. The diagnosis of mental retardation should not be allowed to obscure the presence or severity of an emotional illness, nor should it restrict treatment options. Thus, although the remainder of this paper describes the use of psychotherapy for the treatment of "minor" mental illnesses, so named because they are far less disruptive to others, it is not intended as a panacea. The decisions to recommend psychotherapy, to choose individual or group sessions, or to combine psychotherapy with medication can only be made after a careful assessment and complete diagnosis.

\section{PSYCHOTHERAPY}

Turecki (21) emphasizes that all retarded individuals experience significant adjustment difficulties because of the discrepancy between expectations, demands, and resources. These "minor" mental illnesses are extremely distressing to individuals whose ability to comprehend and self-regulate affects is limited. Although psychotherapy has been an effective treatment, operantconditioning aimed at elimination of the behavioral manifestations of inner distress has been a more common approach (11). 
The goals of individual or group therapy with mentally retarded persons has varied from a conservative behaviorist-like emphasis on the improvement of behavior (15) to an attempt to "partially or wholly restore the intellectual faculty" (5). Current thought on the goals of insight-oriented psychotherapy with mildly mentally retarded individuals, as summarized by Bernstein (3) reflect common goals of all such therapy:

1. To alleviate symptoms that are painful

2. To improve socially unacceptable behavior

3. To accumulate positive affective experiences

4. To realize full potential by removing impairing psychiatric disturbance

5. To accumulate knowledge

Selan (14) lists similar goals, adding the development of emotional maturity and the reinforcement of coping mechanisms. Szymanski (20) and Smith (16) emphasize the need to allow and encourage the exploration of the meaning of "being retarded". Therapy offers an opportunity for the "controlled ventilation” (8), understanding and acceptance of fearful emotions, such as anger and jealousy.

The role of the therapist in dynamically based psychotherapy with mentally retarded individuals requires activity and supportive directness $(8,9)$. The therapist must feel comfortable bridging comments, finishing fragmented thoughts, summarizing discussions, and formulating questions $(19,8,14)$. Clarity is extremely important; topics and goals must be restated and frequently underscored (3).

The therapeutic relationship serves as a new experience for individuals whose interpersonal relationships are often constricted, dominated by guilt and overt rejection (abandonment) or covert rejection (overprotection) $(8,18)$. Interpretations concerning fear of loss of love, denial of affect, the meaning of physical complaints or maladaptive behavior can be made effectively if expressed by the therapist in simple terms with a willingness to repeat. The therapist must remain receptive to expressions of confusion or bewilderment $(20,22)$. The therapist serves as a role model, who in an openly direct and supportive way lends his/her communication skills to examine these forbidden feelings and behaviors in a non-punitive way.

The use of group psychotherapy, as described by Szymanski (20) has a number of advantages (if the individual, based on evaluation, is an appropriate candidate) over individual therapy which include: an opportunity to improve receptive and expressive communication skills in a peer setting; the use of group confrontation of maladaptive behavior; an opportunity to verbalize and share feelings about dependency, retardation, and sexuality. When group members are unable to tolerate the anxiety aroused by direct discussion, displacement techniques such as role playing $(22,2)$ in which a problem is acted out by group members, discussed and then replayed with the discussed modifications, can be 
effective. The use of group therapy also maximizes access to a limited number of therapists.

Using goals similar to those previously discussed, Szymanski provides a model for goal oriented, time limited group psychotherapy which he divides into five overlapping phases: the introductory phase; the first phase characterized by silence, complaining and safe topics; the second phase identified by a willingness to address emotionally charged themes; the third phase marked by problem solving, activity and group cohesion; the termination phase ushered in by concerns about future plans and anxiety; the termination phase which focused on an attempt to assess behavioral change.

The group process detailed in the following case study was divided according to the Szymanski model.

\section{THE GROUP}

The group consisted of eight individuals attending a vocational day program for the mentally retarded. As is often the case in working with the mentally retarded, there were few self referrals (20). Prospective group members were obtained through discussions with case workers who were asked for names of their mildly retarded clients who would benefit from a group therapy experience. Each prospective member was approached by the therapists and asked about their interest in joining a group that would meet for ten weeks to "talk about problems such as making and keeping friends, and any other worries and concerns." With few exceptions, everyone approached expressed interest, although scheduling conflicts prevented a number of clients from participating.

The final group consisted of five women and three men who functioned in the mildly retarded to borderline level of intellectual functioning, with IQ scores ranging from 60 to 78 . All eight members who agreed to participate finished; few missed any sessions. Group sessions were held in a large conference room on the second floor, which seemed to add a degree of mystery and prestige to the process. Nine of the sessions were videotaped. Group members were aware of the taping and signed consent forms.

Both therapists (a psychiatry resident and social worker, who specialized in working with the mentally retarded) had previous training in dynamic psychotherapy, but had limited group experience with no prior group experience with the mentally retarded. Initial expectations were that the group would be time limited (10 weekly, one-hour sessions). General goals were identified before the group began, including: 1) the improvement of communication skills; 2) verbalization of feelings; 3) examination of dependency and friendship; and 4) the meaning of "being retarded". The sessions remained flexible; the goals were used as general guidelines for the therapists rather than "chosen topics."

Group members sat randomly in a semi-circle. After the first session, the therapists avoided sitting together in an attempt to diffuse the tendency for the group to focus on the therapists. 


\section{The Introductory Phase}

Group members and co-therapists introduced themselves. Group members were asked about prior group experiences and present expectations. Two basic "rules" were presented: 1) the need for confidentiality, stressing that members could feel free to express themselves only if everything remained "in the group," important to emphasize since most of the group members worked together on a daily basis; and 2) the importance of listening. Communication problems were obvious, with several group members turning away and interrupting. There was a tendency also to direct all comments to the therapists. Interruptions and inattention was pointed out and explored rather than reprimanded. Group members were often asked to summarize what a prior speaker had discussed. Listening skills were discussed and practiced in all sessions. The major metaphor expressed centered around fears of "too much freedom and not enough rules," hurting others (giving sugar to a diabetic client) and being hurt (managing friends with violent tempers).

\section{Phase 1: (Session 2, 3)}

Two group members joined at the second session, necessitating a brief review which emphasized the importance of the two rules. Each group member was asked to describe his/her goals for the remaining sessions. These included a variety of thoughtful responses from a wish to "look people in the eye when I talk," "not to interrupt" and to "improve and make friends." Only one group member expressed that she had no goals; she was invited to share other's goals. The group discussed the definition of friends.

\section{Phase 2 (Session 3, 4)-Phase 3(Session 4, 5, 6, 7, 8, 9)}

During this working phase, the group began to tackle the fears they shared, beginning with concrete examples: airplanes, amusement park rides, dogs, and elevators. The group discussion of elevator fear marked a dramatic change. The subject remained focused as different group members listened carefully and supportively offered suggestions to control the "panic" they had all experienced. Once the fear of losing control, of not knowing what to do in a situation, was clarified for the group as central to the feelings of panic (this was accentuated by the interruption of the session for a practice fire alarm, which generated a lengthy discussion of security and concern), another shift occurred. The loss of family and the possibility of independent living and group home placement was discussed, with group members offering experiences, advice, and support.

The intensity of these two sessions seemed to necessitate a defensive group withdrawal. The next two sessions were filled with complaining "I'm trying to help myself, not listen to other people's problems," interruption, inattention, 
and a return to focusing upon the therapists. In order to address the breakdown in group communication, a role playing exercise emphasizing effective ways to respond to other's inattention was received enthusiastically by all group members. Feeling less overwhelmed and helpless, the group was then able to acknowledge and share the "hurt inside" when one feels ignored as well as the frustration they all face when expected to "wait until everyone else finishes talking first."

The remaining sessions usually began with a review, often initiated by group members. The group continued to work more cohesively, addressing the painful issue of name calling. This brought a variety of associations which finally led to a discussion of "being retarded." Few group members considered themselves retarded, choosing labels such as "brain damaged" or "slow learner." The meaning of these words as well as special education experiences and various opinions on the need for supervision was discussed.

\section{Termination (Session 10)}

Despite frequent comments by the therapists that the sessions were ending (including an acknowledgement of the "half-way point"), termination was not discussed by group members until the last session. The group again requested a review and then began expressing sadness that the group would be dissolved. Some mourned the loss of "special status." Others discussed their future plans and a review of their initial goals.

The theme of unfinished business emerged, expressing anger that "there's no one to talk to about my feelings." Questions were raised about future groups and all were encouraged to participate as opportunities arise, while at the same time acknowledging their feelings of loss.

\section{FOLLOW-UP}

Measurement of the actual results of such a group is difficult since any observable change in adaptation or behavior could be attributed to a variety of sources. Did the group meet its goals? The time limited format, using ten sessions, provided sufficient time to identify and begin discussion of the pre-established goals without the need to dictate an agenda to group members. An ongoing group format would allow deeper exploration but would decrease availability of the group experience. Is there evidence that the obvious improvement in communication skills within the group generalized to other situations? What were the effects, if any, of verbalizing fear and anger and confronting the reality of being "mentally retarded"?

There is no evidence that the group experience proved harmful to any group member. A seven-month follow-up reveals that all participants continue to work within the vocational program. One group member has been successful in moving from home to a supported-apartment program. Another has success- 
fully enrolled in weight watchers. One group member has had more difficulty with argumentative behavior, while the remainder are described as basically "unchanged." Would they volunteer to participate in another group experience? How do ex-group members perceive their experience? As the number of therapists interested in organizing these groups increases, group data and follow-up data will become more available.

\section{CONCLUSION}

Psychiatrists are potentially well-suited for work with the mentally retarded, possessing a medical background which facilitates understanding of the diverse etiologies and complications arising from commonly associated physical handicaps. Their unique expertise in the evaluation and treatment of the vast spectrum of coexisting emotional illnesses does not explain the disinterest and disdain in treating these individuals.

Although clinical experience and education can confront many of the psychiatrist's biases towards treating the mentally retarded, the largest handicap remains his/her countertransference (18). Treating patients with irreversible defects stirs up feelings of impotency and anger at the inability to "cure." Prescribing medication or exerting punitive behavioral controls may serve as concrete expressions of the need to "do something." Others may become "bleeding hearts" (14) who adopt a pseudo-accepting "anything goes" attitude which is confusing and counterproductive to a mentally retarded individual struggling to maintain a balance between expression of impulses and self control.

The problem is not that psychotherapy cannot work with a person who is mentally retarded; the problem is not that mental retardation insulates a person from emotional distress, making psychotherapy unnecessary; the major problem is the difficulty that psychotherapists, including psychiatrists, encounter when forced to confront fears of their personal limitations, doubts of intellectual abilities-their own fear of being judged retarded.

\section{REFERENCES}

1. Beitchman JH: Disorders of language, communication and behavior in mentally retarded children from psychiatric perspectives on mental retardation. The Psych Clin N Am 9(4):689-698, Dec 1986

2. Bergman $\mathrm{J}$ : The use of paradox in a community home for the chronically disturbed and retarded. Fam Proc 19(1):65-71, 1980

3. Bernstein N: Psychotherapy of the retarded adolescent. Adol Psych 12:406-413, 1985

4. Friedman H, Kaplan H: Mental Retardation. Chapter 30, in The Modern Synopsis of CTP-III. New York, Williams \& Wilkins, pp. 709-731, 1980

5. Gair D, et al: Successful psychotherapy of severe emotional disturbance in a young retarded boy. J Am Acad Child Psych 19:257-269, 1980 
6. LaPierre L: Pharmacologic management of aggressivity and self-mutilation in the mentally retarded from Psychiatric perspectives on mental retardation The Psych Clin N Am 9(4):745-751, 1986

7. Lidz T: The Juvenile. Chapter 9, in The Person: His and Her Development Throughout the Life Cycle. Revised Edition, Basic Books, pp. 273-305, 1983

8. Matson J: Psychotherapy with persons who are mentally retarded. Mental Retardation 22(4):170-175, Aug 1984

9. Menolascino F: Therapy of the mentally retarded. Curr Psych Ther 16:9-19, 1976

10. Munro JD: Epidemiology and the extent of mental retardation, in Psychiatric Perspectives in Mental Retardation. The Psych Clin N Am 9(4):591-624, Dec 1986

11. Reiss S, Levitan G: Emotionally disturbed mentally retarded people: an underserved population. Amer Psych 37(4):361-367, April 1982

12. Reiss $\mathrm{S}$, Benson $\mathrm{B}$ : Awareness of negative social conditions among mentally retarded emotionally disturbed outpatients. Am J Psych 141(1):88-90, Jan 1984

13. Roberts JK: Neuropsychiatric complications of mental retardation from Psychiatric perspectives on mental retardation. The Psych Clin N Am 9(4):647-657, Dec 1986

14. Selan B: Psychotherapy with the developmentally disabled. Health and Social Work $1(1): 73-85$, Oct 1976

15. Simmons J: Treatment and care of the mentally retarded. Psych Annals 47(2):38-69, 1974

16. Smith E: Psychotherapy with the mentally retarded children. Psychoanalytic Study of the Child 31:493-513, 1976

17. Spitzer R (Chair): DSM-III-R, Chapter 3: Disorders usually first evident in infancy, childhood, or adolescence: mental retardation. pp. 28-38, Am Psych Assoc, Washington, DC 1987

18. Symington N: The psychotherapy of a subnormal patient. British J Med Psychol $54: 187-199,1981$

19. Stavrakaki C: Psychotherapies with the mentally retarded, in Psychiatric Perspectives on mental retardation. The Psych Clin N Am 9(4):733-743, Dec 1986

20. Szymanski L: Multiple family group therapy with developmentally disabled adolescents and young adults. Int J Group Psychother 33(4):521-535, Oct 1983

21. Turecki S: The retarded adolescent's future. New York State J Med 23(6):16801682, Oct 1981

22. Weinstock A: Group treatment of characterologically damaged, developmentally disabled adolescents in a residential treatment center. Int J Group Psychother 29(3):369-381, 1979 